\title{
[Title]
}

(1) Manuscript Title: Recent increase of pertussis in South Korea: age-period-cohort analysis

(2) Type of manuscript (Category): Original research

(3) Full authors' names and affiliations

- Chanhee Kim(M.P.H., R.N.), Department of Disease Control Policy, Gyeonggi Provincial Government, Suwon-si, Gyeonggi-do, South Korea (ORCID: 0000-0003-0441-4107)

- Seonju Yi(Ph.D., D.V.M.), Central Disease Control Headquarters, Korea Disease Control and Prevention Agency, Cheongji-si, Chungcheongbuk-do, South Korea (ORCID: 0000-0002-8525-213X)

- Sung-il Cho(Ph.D., M.D.), Graduate School of Public Health, Seoul National University, Seoul-si, South Korea (ORCID: 0000-0003-4085-1494)

(4) Information about funding sources: None

(5) Corresponding author's name, address, and e-mail address

- Name: Sung-il Cho

- $\quad$ Address: Graduate School of Public Health, Seoul National University, Seoul-si, South Korea

- E-mail: $\underline{\text { scho@snu.ac.kr }}$

(6) Short running head: Resurgence of pertussis in S. Korea: APC analysis

(7) Conflicts of interest: There is no any relevant conflicts of interest. 


\section{Recent increase in pertussis incidence in South Korea: An 2 age-period-cohort analysis}

\section{ABSTRACT}

5 Objectives Pertussis or whooping cough, one of the most contagious diseases, is caused by the gram-negative 6 bacterium Bordetella pertussis. Despite the high vaccination rate, South Korea recently experienced a 7 resurgence of pertussis. This study explores the patterns and possible explanations of the resurgence of pertussis 8 in South Korea using age-period-cohort analysis.

9 Methods Using secondary data from the infectious disease portal of Korea Disease Prevention \& Control 10 Agency and Korea Statistical Information Service of Statistics Korea, this study analyzed the incidence of pertussis in South Korea to determine the factors contributing to the recent phenomenon using an age-periodcohort model.

Results Age effects indicated the most vulnerable age group to pertussis as those aged 0-2 years. The period effect showed a sharp increase after 2016. With the cohort effect, a significant decrease was observed from the beginning till the 1955 birth cohort. However, the risk started to increase again with the 2000s birth cohort.

Conclusions Three main possible explanations for our results are consistent with previous studies. First, the occurrence of pertussis was attributed to the contact rates. Second, opportunity for boosting immunity through natural exposure to the pathogen decreased due to the reduced number of circulating pathogens, in turn affecting the trend of pertussis. Lastly, the recent trends were also explained by variations in pathogens. Considering that the most significant increase in the incidence occurred in infants aged below 1 year, it is important to establish sufficient maternal immunity to provide passive immunity via the placenta for the infants. 
Pertussis, one of the most contagious diseases, is caused by a gram-negative bacterium, Bordetella pertussis [1]. $B$. pertussis infection damages the ciliated respiratory epithelium and can lead to functional failure and inflammation of the respiratory tract $[2,3]$. Another name for pertussis, whooping cough, originated from its distinguishing symptom generating a "whoop" sound during inhalation due to the narrowed airways $[1,2,4]$. Humans are the only known host of B. pertussis [1]. Usually, only young children are known to develop pertussis, but anyone, regardless of age, can be affected $[4,5]$. However, infants are the most vulnerable population to pertussis because of their immature respiratory systems and incomplete vaccination schedule [4]. Adolescents and adults experience relatively mild symptoms [5], but they can be a vector of pertussis to vulnerable populations, including infants and children who are fully unimmunized [6].

According to the World Health Organization (WHO), the numbers of pertussis cases and deaths have decreased significantly with the increased proportion of diphtheria-tetanus-pertussis (DTP3) vaccination coverage since the 1980s (Figure 1) [7]. While the global burden of pertussis has decreased substantially, nationally, the burden of pertussis varies across countries. In low-income countries, it is difficult to obtain the exact estimation due to the poor surveillance systems and the lack of diagnostic tools [8]. Despite these constraints, pertussis is one of the most fatal diseases in babies aged under 1 year in developing countries, contributing $90 \%$ of the disease burden of pertussis worldwide [9].

[Insert Figure 1 here]

Resurgence of pertussis has been reported since the 1980s in the developed countries, including Canada, the United States, Australia, and Europe, despite their high vaccination coverage [10]. This recent pattern of pertussis outbreak has a cycle ranging from 2.0 to 4.6 years [11]. This recent increase in pertussis has rarely been reported in adolescents and adults previously [11]. The increased incidence in adolescents and adults, including siblings and parents, can be a threat to young children who have incomplete immunity against pertussis [12]. South Korea also experienced a resurgence of pertussis since the 2000s, similar to that in other highly vaccinated countries, including outbreaks in schools and postpartum centers [2, 13-15]. The outbreak pattern is also similar to that in other highly vaccinated countries, which have a cycle of 2-3 years [2].

Many studies have attempted to determine the reason for pertussis resurgence, including the relatively short immune duration of the $\mathrm{DTaP}$ vaccine $[4,16]$, genetic changes in circulating pathogens [17-19], and reduced opportunities of boosting natural immunity due to decreased incidence [20]. However, the resurgence of a disease cannot be explained by a single factor. The age, period, and cohort effects may provide appropriate explanations to describe the mixed effects of various factors. In this study, we compared the results of an ageperiod-cohort analysis with the results of preceding studies to explain the causes of the re-emergence of pertussis in South Korea and provide a basis for policy development to prevent the disease.

\section{SUBJECTS \& METHODS}

Pertussis cases and mid-year population data were gathered to calculate the annual age-specific incidence of pertussis. In South Korea, all cases of pertussis should be notified by all the physicians including laboratoryconfirmed and clinically suspected cases once identified. The aggregated data of notifiable diseases were obtained from the infectious disease portal of the Korea Disease Prevention \& Control Agency (KDCA, http://www.kdca.go.kr/npt). This study used the age-specific pertussis data from 2001 to 2018. In addition, agespecific mid-year population data were obtained from the Korea Statistical Information Service of Statistics Korea (http://www.kosis.kr).

Using the open data from the infectious disease portal, trends of pertussis were analyzed by age, year, and case definition. KDCA established the reporting case definition classifications as confirmed or suspected cases [21]. A confirmed case is defined as a person who presents pertussis-compatible clinical symptoms and has a positive 
laboratory test result. Suspected cases are defined as individuals whose clinical symptoms and epidemiological relationship suggest pertussis; however, laboratory tests results are unavailable [21]. In the open data source used for the current study, annual age-specific data are provided as the total number of cases, without stratification by the classification (confirmed and suspected cases). We used the total number of cases for our main analysis, and additionally presented the annual trend by case classification without the age information.

South Korea started the DTwP vaccination in 1955, which was changed to the DTaP vaccine in 1989 due to safety issues. These indicate that the people who were born before 1955 (the before 1955 cohort) had not received any artificial immunity, the 1955 to 1988 birth cohorts received the DTwP vaccine, whereas the after 1988 birth cohorts (born after 1989) received the DTaP vaccine.

Before the age-period-cohort (APC) analysis, we described the annual age-specific incidence of pertussis per age group using the infectious disease portal (pertussis cases) and Korea Statistics (mid-year population) data. Age was divided into seven groups: infants ( 0 years), toddlers (1-3 years), preschoolers (4-6 years), schoolaged (7-11 years), adolescent (12-19 years), adult (20-59 years), senior young (60-74 years), and senior old ( $\geq 75$ years). This grouping was used to identify the different patterns of change between the age groups.

Goodness-of-fit statistics was based on the assumption that all three of the age, period, and cohort effects occurred and needed to be estimated simultaneously [22]. By evaluating the model fit statistics with possible sets and combinations of coefficients, age (A), period (P), cohort (C), age period, age cohort, period cohort, and APC, the best model can be identified [22]. The deviance of a model close to the degree of freedom (df) indicates that the model is well-fitted, whereas a large deviance indicates a poor fit of the model [23].

APC analysis is a type of multiple regression that is composed of three time-varying components: age, period, and cohort [24]. It is usually used to suggest a hypothesis on an identified health problem. A recent study on scarlet fever and varicella also used APC analysis to explain the recent increase in disease burden in South Korea [25, 26]. APC analysis is also applicable to non-communicable diseases. A well-known study in the general population used APC analysis to explain the cause of the sharp increase in thyroid cancer incidence in South Korea to be related to thyroid screening [27].

The age effect, a consequence of aging, includes an accumulation of exposures to risk and physiological changes to the body due to aging $[24,28]$. The period effect results from historical events, the economic status at the time, and the availability of new medical techniques [24]. The previous study on the increase in thyroid cancer incidence in South Korea explains the period effect phenomenon due to the expanding screening for thyroid cancer [27]. The cohort effect refers to an effect shared among a specific population born in the same year [29]. For example, Choe et. al. showed that the cohort who were vaccinated for mumps with the ineffective Rubini strain likely contributed to the resurgence of mumps [30]. Further information on the methodology is available in the Supplementary material.

The Poisson APC model was adopted to estimate the age, period, and cohort effects on the trend of pertussis incidence during 2001-2018 in South Korea. The formula for the model is as follows: $\ln [\lambda(a, p)]=f(a)+g(p)+$ $\mathrm{h}(\mathrm{c})$, where $\mathrm{a}, \mathrm{p}$, and $\mathrm{c}$ stand for age, period, and cohort effect, respectively.

However, because of the linear-dependent relationship between the three variables (cohort = period-age), APC model fails to meet the basic assumption of multiple regression that each variable is independent of one another, which is referred to as an "identification (ID) problem" [24]. To manage the identification problem arising from the linear dependence of the three factors, we applied the intrinsic estimator (IE) method [24]. The IE method is less subjective than traditional constraining model (constrained general linear models [CGLM]) by which a researcher chooses one variable out of the three to constrain [31].

Plotting of the incidence by age group, as described earlier, is useful to understand the overall trend of the disease, but it is necessary to set equally spaced blocks for the APC analysis. Blocks were set by 3 yearly unit of age, calendar year, and birth cohort. Patients aged over 80 years were excluded because of their low incidence of pertussis (67 of 2,268; $0.03 \%$ ), resulting in 27 age groups from $0-2$ to $78-80$-year-olds; 18 calendar years during 2001-2018; and 32 birth cohorts from 1923-1925 to 2016-2018. However, after excluding the data of 
individuals over 80 years, there were several cells with missing values. To analyze data with sufficient sample size, the lowest incidence was replaced with a zero value [32]. All the statistical analyses were performed using Stata Statistical Software:Release 13 (College Station, TX: StataCorp LP. StataCorp).

\section{RESULT}

Figure 2 shows the secular trend of pertussis incidence during 2001-2018 in South Korea. The incidence of all eight groups increased after 2017, and the highest incidence occurred in 2018. With the highest incidence, the infant group (0-year-old) showed the highest increase during 2017-2018; followed by the school-aged group (711-year-olds). Table 1, which shows the incidence of pertussis cases by age and calendar year, shows a 17.6-fold increase in infants in 2018 compared with that in 2001. In addition, the school-aged group showed a 93.5-fold increase in 2018 compared with that in 2011, when the incidence was close to zero. This was the most explosive increase among all age groups, similar to that in many other highly vaccinated countries.

[Insert Figure 2 here]

[Insert Table 1 here]

The secular trend of pertussis by case classification and outbreak occurrence are shown in Figure 3. Outbreaks 1-4 represent the reported outbreaks in South Korea. Outbreak 1, which occurred in Yeongam-gun in 2012, occurred in middle and high school dormitories [2,14]. Outbreaks 2 and 3 occurred in postpartum care centers in Andong-si and elementary schools in Changwon-si in 2015, respectively [2, 15]. The last outbreak reported in 2017 included that of Gwangju-si in Gyeonggi-do and Sejong-si [2, 13]. For outbreaks 2 and 3, all cases were confirmed by laboratory tests, whereas suspected cases were also included during the investigation of other outbreaks.

\section{[Insert Figure 3 here]}

For APC analysis, the result of the goodness-of-fit test suggested that the full APC (IE) model fitted best (Table 2). The residual deviance represents the goodness-of-fit of the models. According to residual deviance, the full APC model, which showed the smallest residual deviance, most appropriately explained the data.

\section{[Insert Table 2 here]}

The effects of age on the incidence of pertussis are shown in Figure 4. The results indicate that the most vulnerable age group to pertussis was the 0-2-year-old group, including infants who received the initial three doses of DTaP vaccination. After the third vaccination, there was a sharp decrease in the risk of pertussis in 3-5year-olds. However, the risk increased again in the 9-11-year-olds, and then the second decrease occurred until the age of 54-56 years. After the lowest point at 54-56 years of age, the risk increased again until the last age group.

\section{[Insert Figure 4 here]}

The period effect was also significant, as shown in Figure 5. During 2001-2015, there were no significant changes in the risk of pertussis. From 2016, the risk of pertussis sharply increased, showing a similar trend in the overall incidence of pertussis in South Korea from 2001-2018.

\section{[Insert Figure 5 here]}

Another increased risk of pertussis was observed in the cohort effect (Figure 6). The risk of pertussis increased gradually until the introduction of vaccination in 1955. After that, there was a steady decrease in the risk of pertussis until the early 1990s' birth cohorts. Since the 2000s birth cohort, the risk began to increase again to as high as it was before the vaccine was introduced.

\section{[Insert Figure 6 here]}




\section{DISCUSSION}

161 We described the secular trend of pertussis incidence and estimated the effects of age, period, and cohort during in South Korea. The most significant increase was observed in the infant, school-aged, and preschooler groups. The exceptionally high proportion of adolescents in 2012 seemed to have resulted from the pertussis outbreak in middle and high school dormitories. During 2001-2018, the average reported number of cases in adolescents was 17.1 cases per 100,000 persons. However, in 2012, a total of 157 cases were reported, among which 113 were from high school and 41 from middle school in Yeongam-gun [14].

Given that the routine vaccination schedule of the DTaP vaccine includes a 5-dose series given at 2, 4, 6, and 15-18 month and 4-6 years, the age effect showed a preventive effect after the first 5 doses of the vaccination, which were completed at ages 4-6 years. Despite its effectiveness, the risk increased soon after, at the age of 68 to 9-11 years. This suggests a scientific rationality of the vaccination schedule of the Tdap vaccine, which is recommended at 11-12 years. We can infer that this occurred due to the increased contact rate in the school environment. According to a study regarding the age-specific contact rate of respiratory diseases, the highest contact rate was observed at 10-14 years [33]. Studies supporting this pattern of contact rate have been conducted in Japan and the Netherlands. In Japan, elementary school children are more vulnerable to pertussis than junior high school students because of their lower exposure rate to pertussis [34]. Similarly, in the Netherlands, the children who completed their 5-dose vaccination doses already had sufficiently high-level immunity at 9 years of age owing to natural immunity boosting [35].

The age-specific contact rate also explains the decreasing pattern that occurred after 9-11 years of age wherein age-specific contact rates begin to decrease at 15-19 years [33]. In addition, in Korea, the School Entry Requirement of Certification Program conducted by the KDCA, in not only elementary schools but also middle schools, requires the Tdap immunization certification. This vaccination boost may be attributed to the decrease in the risk from reaching ages 9-11 years.

From the results of age effect, we can conclude that despite the lowered incidence, there were still circulating pathogens of pertussis to stimulate the immunity boosting reaction. This effect may accumulate with age, resulting in a decreasing trend of risk until the middle age. Lastly, the increasing trend observed at over 60 years indicates a lowered immunity with age [36].

The period effect over the risk of pertussis was also significant, with the sharpest increase in risk occurring during 2016-2018. Based on the overall incidence (Figure 2), the most significant increase in pertussis occurred in 2018, and the result of the period effect reflects this pattern. Three possible explanations have been suggested in previous studies. First, is the antigenic variants that do not correspond to the vaccine type [37]. In Korea, the type of circulating pathogen in 2011-2012 was different from that in 2000-2009 [37]. This previous study also revealed that changes in genotypes in South Korea have emerged notably, especially in genes that determine antigenicity, as has already been reported in many other countries [37].

Second, other research supports the decreased opportunity of natural immunity boosting due to the reduced number of circulating pathogens [20]. Because of the decreased force of infection due to lowered incidence, the size of the population without any re-exposure to the pertussis pathogen grows bigger than in the past [20]. At some point, accumulation of this population across the threshold of protection results in a rapid increase in the incidence of pertussis [38].

Lastly, the outbreak of Middle East respiratory syndrome (MERS) in 2015 increased the healthcare providers' awareness of respiratory diseases. Since the reporting criteria for pertussis include suspected cases, the sharp increase starting from the 2013-2015 calendar year reflects the situation of South Korea in 2015 regarding the MERS outbreak. The effect of the MERS outbreak on reporting behavior has also been described in previous 
research, in which an interrupted time series analysis results showed an increase in the overall report of notifiable diseases, since the MERS outbreak [39].

According to the results of the cohort effect shown in Figure 6, the risk of pertussis increased until the introduction of the DTwP vaccine in 1955. From the 1955 birth cohort, the risk began to drop until the late 1990s birth cohorts. The resurgence of risk beginning with the 2000s birth cohort may have been induced by reduced maternal passive immunity. During the pre-vaccine era, the most vulnerable population was not the infants aged under 1 year but the toddlers aged $1-4$ years [40, 41]. Moreover, during the pre-vaccine era, case fatality rates of pertussis were higher in the 2- and 3-month-old infants than in 1-month-old infants; representing the indirect evidence of maternal immunity transfer to the infants [42]. However, waning immunity after vaccination, accompanied by a decreased rate of circulating pathogens, makes it difficult for pregnant women to have sufficient antibodies against pertussis to transfer to their newborn [42]. The increased risk of the 2000s birth cohort represented by the cohort effect may have resulted from the decreased immunity of the mother cohorts.

In summary, three main possible reasons were suggested by previous studies to explain the results of our study. First, the contact rates were attributed to the occurrence of pertussis. As mentioned earlier, the pattern of the age effect can be explained by the age-specific contact rates. Exceptional patterns at both ends are explained by the occurrence of vaccination during childhood and decreased immunity with age, respectively.

Second, another factor affecting the trend of pertussis is decreased opportunity for natural immunity boosting due to the lowered number of circulating pathogens. The introduction of vaccines result in decreased incidence, but they also result in the accumulation of susceptible populations due to the combined effect of waning immunity after vaccination and the absence of natural immunity boosting. This finding is linked to a decrease in passive immunity from the mother, which is represented by the cohort effect. The mothers of the recent birth cohort (2000s) were the generation that were vaccinated during their childhood, yet, they also experienced decreased incidence of pertussis not sufficient to induce natural immunity boosting.

Lastly, variation in pathogens is suggested to explain recent trends in pertussis. This variation is supported by a serological study conducted in South Korea. It is assumed that this variation resulted from the adaptation of the pathogen to the vaccination.

From a public health perspective, providing additional opportunities for immunity boosting is a necessary intervention to improve the current situation brought about by the three factors, which the recent increase in pertussis in South Korea are attributed to. Considering that the most significant increase in the incidence occurred in infants under 1 year of age, it is important to establish sufficient maternal immunity level to provide passive immunity via the placenta for infants who are too young to be vaccinated.

According to a randomized clinical trial conducted in the United States, no increased risk of adverse events were noticed in women or their infants after receiving the Tdap vaccine during weeks 30-32 of pregnancy ; additionally high concentration of pertussis toxin antibodies was observed in infants during the first two months and no altered infant response to DTaP was observed [43]. Another randomized controlled trial conducted in the Netherlands also indicated that maternal immunity during pregnancy prevented neonates from contracting pertussis [44].

Although our study findings are consistent with those of previous studies, this study has a few limitations. First, considering the relatively low reporting rates of vaccine-preventable diseases (VPD) compared with of other notifiable diseases, the entire disease burden of pertussis could have been underestimated in this study. According to a previous study that calculated the reporting and claim ratio ( $\mathrm{R} / \mathrm{C}$ ratio) of infectious diseases in South Korea, none of the VPDs showed an R/C ratio close to 1, neither did it exceed 0.5 [39]. Second, these data do not provide information about vaccination history, indicating that the study results simply assumed the effect of vaccination. In future studies, information about vaccination history may enable determining the exact effect of vaccination by calculating the attack rate of pertussis among the vaccinated population. Third, the fundamental limitation of the APC analysis is that the tool cannot determine an exact association between the 
putative causal factors and the phenomenon. We can explain the phenomenon resulting from the APC analysis based on existing studies; however, no direct measurement of potential deteminants was included in this study.

252 Lastly, due to the inclusion of suspected cases in the analysis, the result of our study should be interpreted carefully because some of the suspected cases may be false positives. If certain age groups, especially the youngest or the oldest groups, involve higher proportion of suspected cases, the relative risks among these age groups might have been somewhat overestimated in the age effect curve.

Despite these limitations, this study provides epidemiological evidence on the patterns of pertussis in South Korea. Further data on vaccination histories and age-specific data from previous periods would enable more accurate estimates. In conclusion, this study identified the age, period, and cohort effects of pertussis in South Korea. The standard vaccination schedule in South Korea mainly focuses on children. However, this study suggests the necessity for adult vaccination, especially for pregnant women, through an APC analysis. South Korea is one of the countries with the best prenatal care. It is necessary to promote the importance of maternal vaccination through cooperation with local hospitals during the prenatal stage, and the relative exclusion of pregnant women from national vaccination projects should be addressed.

\section{Ethics Statement}

The institutional review board of OOO University waived the need for ethics review considering that all data

\section{Conflict of Interest}

The authors have no conflicts of interest to declare for this study.

\section{Acknowledgements}

We would like to express my gratitude to Dr. Hee-Won Kang, who taught us the APC method from A to Z.

\section{Author Contributions}

Conceptualization: SY. Data curation: CK. Formal analysis: CK. Methodology: CK. SIC. Visualization: CK.

\section{ORCID}

\section{Key Message}

높은 예방접종률에도 불구하고 한국은 최근 백일해 재출현을 경험하고 있으며, 이는 다른 선진국에서도 1980 년대부터 이미 보고되고 있던 현상이다. 본 연구는 연령-기간-코호트 분석을 
재출현에 영향을 끼친 것으로 나타났다. 많은 선행 연구를 통해 제시되었던 연령대별 접촉 양상의 차이, 순환하는 병원체의 감소로 인한 자연 추가 접종 기회의 감소, 그리고 항원 변이가 최근의 백일해 재출현을 설명하는 이론으로 제시되었다. 세 가지 이론 중 공중보건학적 중재가 가능한 가설은 추가 접종의 기회를 제공하는 것이다. Tdap 접종은 한국에서 성인에방접종일정에서 권고되고 있음에도 불구하고 예방접종률은 매우 낮다. 성인을 대상으로 Tdap 접종의 중요성을

\section{REFERENCES}

1. Kilgore PE, Salim AM, Zervos MJ, Schmitt HJ. Pertussis: microbiology, disease, treatment, and

2. Korea Disease Control and Prevention Agency, Epidemiology and management of vaccine preventable

3. Paddock CD, Sanden GN, Cherry JD, Gal AA, Langston C, Tatti KM, et al. Pathology and pathogenesis of fatal Bordetella pertussis infection in infants. Clin Infect Dis 2008;47:328-338.

4. Sealey KL, Belcher T, Preston A. Bordetella pertussis epidemiology and evolution in the light of pertussis resurgence. Infect Genet Evol 2016;40:136-143.

5. Ebell MH, Marchello C, Callahan M. Clinical Diagnosis of Bordetella Pertussis Infection: A Systematic Review. J Am Board Fam Med 2017;30:308-319.

6. Wendelboe AM, Njamkepo E, Bourillon A, Floret DD, Gaudelus J, Gerber M, et al. Transmission of Bordetella pertussis to young infants. Pediatr Infect Dis J 2007;26:293-9.

7. World Health Organization, Data on pertussis cases, estimated deaths and vaccination coverage. [cited 2019 Jan 29]; Available from: https://www.who.int/immunization/monitoring_surveillance/burden/vpd/surveillance_type/passive/pert ussis/en/.

8. Yeung KHT, Duclos P, Nelson EAS, Hutubessy RCW. An update of the global burden of pertussis in children younger than 5 years: a modelling study. Lancet Infect Dis 2017;17:974-980.

9. Bamberger ES, Srugo I. What is new in pertussis? Eur J Pediatr 2008;167:133-139.

10. Chiappini E, Stival A, Galli L, de Martino M. Pertussis re-emergence in the post-vaccination era. BMC Infect Dis 2013;13:151.

11. Broutin H, Viboud C, Grenfell BT, Miller MA, Rohani P. Impact of vaccination and birth rate on the epidemiology of pertussis: a comparative study in 64 countries. Proc Biol Sci 2010;277:3239-3245.

12. von König CH, Halperin S, Riffelmann M, Guiso N. Pertussis of adults and infants. Lancet Infect Dis 2002;2:744-750.

13. Korea Disease Control and Prevention Agency, Infectious diseases surveillance yearbook: Chungbuk; 2017.

14. Korea Disease Control and Prevention Agency, Infectious diseases surveillance yearbook: Chungbuk; 2012.

15. Korea Disease Control and Prevention Agency, Infectious diseases surveillance yearbook: Chungbuk; 2015. 
16. Ausiello CM, Cassone A. Acellular pertussis vaccines and pertussis resurgence: revise or replace? mBio 2014;5:e01339-14.

17. Bart MJ, Harris SR, Advani A, Arakawa Y, Bottero D, Bouchez V, et al. Global population structure and evolution of Bordetella pertussis and their relationship with vaccination. mBio 2014;5:e01074.

18. King AJ, van Gorkom T, van der Heide HG, Advani A, van der Lee S. Changes in the genomic content of circulating Bordetella pertussis strains isolated from the Netherlands, Sweden, Japan and Australia: adaptive evolution or drift? BMC Genomics 2010;11:64.

19. Bouchez V, Guiso N. Bordetella pertussis, B. parapertussis, vaccines and cycles of whooping cough. Pathog Dis 2015;73:ftv055.

20. Lavine JS, King AA, Bjørnstad ON. Natural immune boosting in pertussis dynamics and the potential for long-term vaccine failure. Proc Natl Acad Sci U S A 2011;108:7259-7264.

21. Korea Disease Control and Prevention Agency, Guideline for vaccine-preventable infectious diseases: Cheongju, Korea. 2021.

22. Yang, Y, Land, KC. Age-period-cohort analysis: new models, methods, and empirical applications. 1st ed. Boca Raton, FL: CRC Press. 2013

23. Kretzschmar M, Teunis PF, Pebody RG. Incidence and reproduction numbers of pertussis: estimates from serological and social contact data in five European countries. PLoS Med 2010;7:e1000291.

24. Heo J, Jeon SY, Oh CM, Hwang J, Oh J, Cho Y. The unrealized potential: cohort effects and ageperiod-cohort analysis. Epidemiol Health 2017;39:e2017056.

25. Kim J, Kim JE, Bae JM. Incidence of Scarlet Fever in Children in Jeju Province, Korea, 2002-2016: An Age-period-cohort Analysis. J Prev Med Public Health 2019;52:188-194.

26. Kim J, Kim JE, Bae JM. Incidence of varicella in children in Jeju-do, Korea, 2005-2016: age-periodcohort analysis. Epidemiol Health 2018;40:e2018054.

27. Oh CM, Jung KW, Won YJ, Shin A, Kong HJ, Lee JS. Age-Period-Cohort Analysis of Thyroid Cancer Incidence in Korea. Cancer Res Treat 2015;47:362-369.

28. Kenneth CL, Yang Y. Age-period-cohort analysis: Boca Ranton,FL: CRC Press. 1st ed. 2016.

29. Suzuki E. Time changes, so do people. Soc Sci Med 2012;75:452-456; discussion 457-8.

30. Choe YJ, Lee YH, Cho SI. Increasing mumps incidence rates among children and adolescents in the Republic of Korea: age-period-cohort analysis. Int J Infect Dis. 2017;57:92-97.

31. Yang Y, Schulhofer- Wohl S, Fu W, Land, K. The Intrinsic Estimator for Age- Period- Cohort Analysis: What It Is and How to Use It. Am J Sociol 2008;113:1697-1736.

32. Stockard, J, O’Brien RM. Cohort variations in suicide rates among families of nations: an analysis of cohorts born from 1875 through 1985. Int J Comp Sociol; 2006;47:5-33.

33. Mossong J, Hens N, Jit M, Beutels P, Auranen K, Mikolajczyk R, et al. Social contacts and mixing patterns relevant to the spread of infectious diseases. PLoS Med 2008;5:e74.

34. Yasui Y, Mitsui T, Nishimura T, Uchida K, Inokuchi M, Mori M, et al. School-age children and adolescents suspected of having been to be infected with pertussis in Japan. Vaccine 2018;36:29102915.

35. Schure RM, de Rond L, Oztürk K, Hendrikx L, Sanders E, Berbers G, Buisman AM. Pertussis circulation has increased T-cell immunity during childhood more than a second acellular booster vaccination in Dutch children 9 years of age. PLoS One 2012;7:e41928.

36. Mooi FR, Van Der Maas NA, De Melker HE. Pertussis resurgence: waning immunity and pathogen 
adaptation - two sides of the same coin. Epidemiol Infect 2014;142:685-694.

37. Kim SH, Lee J, Sung HY, Yu JY, Kim SH, Park MS, et al. Recent trends of antigenic variation in Bordetella pertussis isolates in Korea. J Korean Med Sci 2014;29:328-333.

38. Aguas R, Gonçalves G, Gomes MG. Pertussis: increasing disease as a consequence of reducing transmission. Lancet Infect Dis 2006;6:112-117.

39. Jung J, Im JH, Ko YJ, Huh K, Yoon CG, Rhee C, et al. Complementing conventional infectious disease surveillance with national health insurance claims data in the Republic of Korea. Sci Rep 2019;:8750.

40. Cherry JD. Pertussis in the preantibiotic and prevaccine era, with emphasis on adult pertussis. Clin Infect Dis 1999;28:S107-S111.

41. George RH. Passive immunity to pertussis in newborns. Pediatr Infect Dis J 1990;9:374.

42. Van Rie A, Wendelboe AM, Englund JA. Role of maternal pertussis antibodies in infants. Pediatr Infect Dis J 2005;24:S62-S65.

43. Munoz FM, Bond NH, Maccato M, Pinell P, Hammill HA, Swamy GK, et al. Safety and immunogenicity of tetanus diphtheria and acellular pertussis (Tdap) immunization during pregnancy in mothers and infants: a randomized clinical trial. JAMA 2014;311:1760-1769.

44. Barug D, Pronk I, van Houten MA, Versteegh FGA, Knol MJ, van de Kassteele J, et al Maternal pertussis vaccination and its effects on the immune response of infants aged up to 12 months in the Netherlands: an open-label, parallel, randomised controlled trial. Lancet Infect Dis 2019;19:392-401. 
386 Figure 1. Pertussis global annual reported cases and diphtheria-tetanus-pertussis (DTP3) coverage, 1980-2017 [7]; DTP3, three doses of DTP3; WHO, World Health Organization; UNICEF, United Nations of Children's 388 Fund.

389 Figure 2. Incidence of pertussis by age groups, South Korea, 2001-2018

390 Figure 3. Number of classification-specific reported cases by year, South Korea, 2001-2018

391 Figure 4. Intrinsic estimator (coefficient) of age effect from age-specific incidence (100,000 person) of pertussis 392 by age groups.

393 Figure 5. Intrinsic estimator (coefficient) of period effect from age-specific incidence (100,000 person) of 394 pertussis by calendar years.

395 Figure 6. Intrinsic estimator (coefficient) of cohort effect from age-specific incidence (100,000 person) of 396 pertussis by birth cohorts. 